\title{
Assessment of Distress Associated to Psychopathology in Children and Adolescents
}

\author{
Lourdes Ezpeleta ${ }^{1}$, Wendy Reich ${ }^{2}$, Roser Granero ${ }^{1}$ \\ ${ }^{1}$ Universitat Autònoma de Barcelona, ${ }^{2}$ St. Louis MO (USA)
}

Disponible online 30 de abril de 2009

\begin{abstract}
El objetivo de este estudio fue analizar el malestar asociado a la psicopatología en niños y adolescentes. La muestra incluyó 330 sujetos entre 8 y 17 años que atendían a consulta externa en servicios de salud mental de la red pública de Barcelona (España), que fueron valorados a través de entrevista diagnóstica estructurada. Una parte significativa de los niños que solicitaron tratamiento sufrían malestar asociado a los síntomas psicológicos interiorizados y exteriorizados. El malestar psicológico fue más frecuente en las chicas y entre los adolescentes y también fue más informado por los propios niños y adolescentes que por sus padres. El malestar fue un predictor de la percepción de necesidad de ayuda psicológica y se relacionó significativamente con los diagnósticos, condiciones subumbral y deterioro funcional. Los síntomas individuales de depresión, distimia, ansiedad generalizada y trastorno negativista desafiante fueron los que más estrechamente se asociaron con el malestar psicológico. Dada la importancia del estrés subjetivo y del deterioro funcional para la identificación y definición de la psicopatología y para la planificación de las intervenciones, la evaluación diagnóstica debería incluir cuestiones referidas al malestar.
\end{abstract}

Palabras clave:

Malestar subjetivo, entrevistas diagnósticas estructuradas y criterio de significación clínica

The aim of this paper was to study the distress associated to psychopathology in children and adolescents. The sample included 330 children aged 8 to 17 years attending outpatient mental health services of the public network in Barcelona (Spain) assessed using a structured diagnostic interview. A substantial part of children brought to treatment suffered distress associated to internalizing and externalizing psychological symptoms. Psychological distress was most frequent among girls and among adolescents, and was more frequently reported by children and adolescents than by their parents. It was also a marker of perception of need of psychological help, and it was significantly related to diagnosis, subthreshold conditions and functional impairment. Individual symptoms of depression, dysthymia, generalized anxiety disorder and oppositional defiant disorder were most associated with psychological distress. Given the potential importance of subjective distress as well as impairment for the identification and definition of psychopathology and planning of treatment, diagnostic assessment should include questions related to distress.

Keywords:

Subjective psychological distress; Structured diagnostic interviews; Clinical significance criterion.

\footnotetext{
This work was supported by grants BSO2002-03850 from the Ministry of Science and Technology and SEJ2005-01786 from the Ministry of Education and Science (Spain).

Correspondence should be addressed to Lourdes Ezpeleta. Departament de Psicologia Clínica i de la Salut. Edifici B. Universitat Autònoma de Barcelona. 08193 Bellaterra (Barcelona) (Spain). Phone: (+34) 9358128 83. Fax: (+34) 9327457 76. E-mail: lourdes.ezpeleta@uab.es
} 
The definition of mental disorders is still a matter of debate. In DSM-IV (American Psychiatric Association, 1994) a mental disorder is conceptualized as "a clinically significant behavioral or psychological syndrome or pattern that occurs in an individual and that is associated with present distress (e.g. emotionally painful) or disability (i.e., impairment in one or more important areas of functioning) or with a significantly increased risk of suffering death, pain, disability or an important loss of freedom" (p. XXI). To date we do not have a clear consensus definition of distress and impairment (Maser et al., 2009). Subjective psychological distress refers to the personal feelings of discomfort, unpleasantness, or emotional pain caused by psychological symptoms, whereas functional impairment refers to the consequences that psychological symptoms or disorders have on the life of the child with respect to performance of everyday functions (Üstun \& Chatterji, 1997).

A distress/impairment criterion (clinical significance criterion) was included in those disorders for which the distinction between normality and clinical disorders could be difficult to make reliably (Antony et al., 1994) in order to avoid the false positive diagnoses. Different criticisms were raised, the most notable were the possible redundancy with the symptoms, increasing false negatives, hindering early case identification or delaying provision of services, or its lack of precision (Lehman, Alexopoulos, Goldman, Jeste, \& Ustun, 2002; Spitzer \& Wakefield, 1999). However, its usefulness is also recognized and lately new proposals about how to implement this criteria in DSM-V are appearing (Drabick, 2009).

DSM-IV requires the presence of impairment or distress for substance abuse and dependence, depressive disorders (major depression -MDD- and Dysthymia -DD), separation anxiety disorders (SAD), generalized anxiety disorder (GAD), obsessive-compulsive disorder (OCD), post-traumatic stress disorder (PTSD), phobias and enuresis. For attention deficit/ hyperactivity disorder (ADHD), oppositional-defiant (ODD) and conduct disorder (CD) and mania, only impairment is required. Finally, for panic disorder, anorexia and bulimia nervosa, encopresis, somatization and tics, neither impairment nor distress are required for these diagnoses. While the DSM-IV usually refers to full diagnostic criteria, different studies have suggested that subthreshold cases, that is, cases that do not meet the full descriptive criteria for a specific disorder but meet the clinical significance criterion of impairment of DSM-IV, should be considered as "cases" (Angold, Costello, Farmer, Burns, \& Erkanli, 1999; Lewinsohn, Solomon, Seeley, \& Zeiss, 2000). Under some circumstances, these may fall under the DSM NOS category although these are usually defined as having impairment. However, very little work has been done on the place of distress in both cases and symptom clusters.

The assessment of distress is important for case definition, treatment planning and treatment efficacy assessment, as well as an indicator of outcomes. With regard to planning treatment, a high level of distress is a relevant motivating variable in kee- ping the patient engaged in treatment (Beutler, Malik, Talebi, Fleming, \& Moleiro, 2004). In a sample of 20 outpatients, Phares and Danforth (1994) observed a high association between distress over adolescents' behavior and motivation to change that behavior. Decrease in subjective distress is also a measure of improvement and it is a way of assessing the efficacy of the treatment. The level of distress moderates treatment outcome: cases with high psychological distress achieve greater treatment improvement that cases with low distress (PanichelliMindel, Flannery-Schroeder, Kendall, \& Angelosante, 2005).

Previous work about subjective distress has centered on questionnaires and has compared children's distress about their problems and parents' and teachers' distress about the adolescent's behavior. It has been shown that the occurrence of a behavior did not necessarily coincide with feelings of distress (Dubow, Lovko, \& Kausch, 1990). Phares and Compas (1990) reported that community adolescents' ratings of subjective distress differed from their perceptions of their parents' distress over the adolescent behavior; adolescents were more distressed by internalizing than externalizing problems but perceived their parents as more distressed by externalizing than internalizing problems. In Phares and Danforth's (1994) clinical study, adolescents reported the least amount of distress about all types of their own behavior while parents reported the highest amount of distress about all types of their adolescents' behavior.

The work done with questionnaires has not been replicated with diagnostic interviews. Many of the structured diagnostic interviews for children and adolescents designed to follow DSM-IV criteria do not ask about distress. However, they do ask about impairment of symptoms at home, at school or with friends, but few assess levels of stress and how emotionally painful the symptoms are for the child or adolescent. With regard to interviews assessing general psychopathology, the Development and Well-Being Assessment (Goodman, Ford, Richards, Gatward, \& Meltzer, 2000) systematically asks the child and the parents if the symptoms bother the child, and the K-SADS-PL (Kaufman et al., 1997) evaluates distress in some sections (anxiety, elimination, racing thoughts). Specialized schedules such as the Anxiety Disorders Interview Schedule (Silverman, Albano, \& Barlow, 1994) also evaluate distress.

How children recognize and report about subjective distress and how their parents report distress in their children because of psychological symptoms has not been previously studied with diagnostic interviews. This question is examined in the current paper. Additionally, we wish to better understand how different diagnostic statuses (symptoms without impairment, subthreshold, and full diagnosis) and individual symptoms relate to psychological distress and the relationships of distress with functional impairment (the other clinical significance criterion), as well as with perception of problems, need for help and use of services. This knowledge can help to prioritize interventions, to better understand the phenomenology of disorders in children and adolescents, and to refine diagnostic criteria. 
Method

\section{Participants}

Children were recruited from two psychiatric outpatient clinics from the public health network in Barcelona (Spain). The sample included 330 consecutively referred children aged 8 to 17 years that represent $91.2 \%$ of those invited to participate. There were $148(44.8 \%)$ girls and $182(55.2 \%)$ boys. Their mean age was $14.0(S D=2.4)$. Following Hollingshead (1975) index, $13 \%$ came from high and mean-high socioeconomic status, $57.4 \%$ from mean and mean-low, and $29.6 \%$ from low.

\section{Measures}

The Diagnostic Interview for Children and Adolescents (Entrevista Diagnóstica para Niños y Adolescentes; EDNA-IV) in its current version, the MAGIC (Reich, 2000; Todd, Joyner, Heath, Neuman, \& Reich, 2003), was used to assess psychopathology. The EDNA-IV covers the most frequent diagnostic categories according to DSM-IV and has been adapted and validated for the Spanish population with similar psychometric properties to the original version (Ezpeleta et al., 1997). A question asking about distress caused by each disorder was included within the interview after impairment questions. Children and parents were asked "Do these feelings/behaviors make you feel bad? Are they painful for you? Are you bothered by them? How much have these feelings/worries/behaviors upset or distressed you?" Following the format of questions of impairment, answers were registered in a four-alternative format (1: Not at all; 2: A little; 3: Fairly; 4: A lot). As in the case of the symptoms and functional impairment, parents were asked if they observed distress in their children because of the symptoms. Clinical significant distress was considered when ratings were 3 or 4 . ADHD were presented only to parents. Disorders that contain the clinical significance criterion in DSM-IV were included for the analyses. Cases who did not meet full criteria for the DSM definition of the disorder but presented impairment at home, school or with friends were considered having "subthreshold disorders" (Pincus, Davis, \& McQueen, 1999).

Information from parents, children and combined parentchild reports were used for the analysis. Combined information considered a symptom or a criterion present if any of the informants reported its presence.

\section{Procedure}

The project was approved by the ethics review committee of the Universitat Autònoma de Barcelona. Informed consent was given by parents. Children and adolescents and their parents were interviewed with EDNA-IV/MAGIC separately by different trained interviewers $(\mathrm{PhD}$ psychologists and $\mathrm{PhD}$ psychology students). Questions about perception of psychological problems and need for help by the child, parent or teachers, as well as use of services were asked to parents and children.

\section{Statistical analysis}

Data were analyzed with SPSS 15.0.1 for Windows. Chisquare and Fisher's exact test were used for non-adjusted independent group proportion comparisons. McNemar chi-square was used for paired proportion comparisons. Binary logistic regression, adjusted by sex and age, was used for analyzing the association between distress and diagnosis and subthreshold conditions, as well as for the contribution of individual symptoms to distress and impairment. Due to the low prevalence of some distress measures and the high asymmetry of contingency tables comparing parents and children's reports, the level of agreement between both informants was measured through the specific agreement for the presence and the absence of a positive response instead of kappa statistics, which would be severely biased for these base-rates.

Bonferroni-Finner correction (Finner, 1993) was applied to avoid type-I error inflation by multiple statistical testing, with the exception of the study of the relationship between different categories of symptoms and distress (Table 4) since no statistical differences were expected for these analyses.

\section{Results}

\section{Sex differences in distress}

Subjective distress was reported by $71.9 \%(95 \%$ CI: $63.5-$ 79.2) of the girls and $60.1 \%$ of the boys ( $95 \% C I: 52.0-67.8)$ $(p=.035)$. Among parents of the girls, 68.0\% (95\% CI: 59.1 - 77.9) reported distress caused by psychological symptoms while $57.1 \%$ of the parents of boys ( $95 \%$ CI: $49.5-64.6)(p=$ $.055)$ reported distress. Combining information from parent and children, $80.4 \%$ of the girls ( $95 \%$ CI: $73.1-86.5)$ and $72.5 \%$ of the boys (95\% CI: 65.4 - 78.9) were distressed by their psychological symptoms $(p=.095)$. Sex differences in self-reported distress were studied for every disorder. Significant differences were found in: MDD (girls: $58.7 \%$, boys: $38.4 \%, p=.009$; combined: girls: $61.7 \%$, boys: $41.1, p=.002$ ), PTSD (girls: $56.3 \%$; boys: $14.3 \% ; p=.062$; combined: girls: $42.3 \%$, boys: $6.7 \%$, $p=.030$ ), and somatization (girls: $0 \%$, boys: $66.7 \%, p=.014$ ).

\section{Age differences in distress}

Percentages of distress reported by children ( 8 to 12 years-old) and adolescents (13 to 17 years-old) were compared. Forty-nine percent of the children (95\% CI: 38.9 - 59.2) and $74.1 \%$ of the adolescents (95\% CI: $67.3-80.1)$ $(\mathrm{p}<.0005)$ reported subjective distress. Fifty percent of the parents of the children ( $95 \%$ CI: $40.3-59.7)$ and $68.4 \%$ of 
Table 1. Differences in Parent and Children Reports of Distress.

\begin{tabular}{|c|c|c|c|c|c|c|c|c|}
\hline \multirow[b]{2}{*}{ Disorders } & \multirow[b]{2}{*}{$\begin{array}{l}N \text { cases with } \\
\text { symptoms }^{1}\end{array}$} & \multicolumn{2}{|c|}{ Children } & \multicolumn{3}{|c|}{ Parents } & \multicolumn{2}{|c|}{ Specific agreement (\%) } \\
\hline & & $\begin{array}{c}N \text { reported } \\
\text { distress }\end{array}$ & $\%(95 \% C I)$ & $\begin{array}{c}N \text { reported } \\
\text { distress }\end{array}$ & $\%(95 \% C I)$ & $p^{2}$ & Presence & Absence \\
\hline Any symptom & 330 & 192 & $58.2(52.7-63.6)$ & 187 & $56.7(51.1-62.1)$ & .81 & 67.5 & 56.2 \\
\hline ADHD & 210 & - & - & 58 & $27.6(21.7-34.2)$ & & & \\
\hline ODD & 190 & 37 & $19.5(14.1-25.8)$ & 54 & $28.4(22.1-35.4)$ & .20 & 26.4 & 76.8 \\
\hline CD & 202 & 37 & $18.3(13.2-24.4)$ & 20 & $9.9(6.1-14.9)$ & .20 & 3.5 & 84.2 \\
\hline Alcohol & 28 & 5 & $17.9(6.1-36.9)$ & 0 & & .20 & 0 & 90.1 \\
\hline Marihuana & 40 & 4 & $10.0(2.8-23.7)$ & 3 & $7.5(1.6-20.4)$ & 1 & 57.1 & 95.5 \\
\hline Other drugs & 8 & 4 & $50.0(15.7-84.3)$ & 0 & & .22 & 0 & 66.7 \\
\hline MDD & 222 & 82 & $36.9(30.6-43.7)$ & 68 & $30.6(24.6-37.1)$ & .23 & 46.7 & 72.8 \\
\hline Dysthymia & 64 & 18 & $28.1(17.6-40.8)$ & 18 & $28.1(17.6-40.8)$ & 1 & 5.6 & 63.0 \\
\hline Mania & 17 & 3 & $17.6(3.4-43.4)$ & 1 & $5.9(0.1-28.7)$ & 66 & & \\
\hline SAD & 103 & 23 & $22.3(14.7-31.6)$ & 13 & $12.6(6.9-20.6)$ & .58 & 27.8 & 84.7 \\
\hline GAD & 162 & 49 & $30.2(23.3-37.9)$ & 28 & $17.3(11.8-24.0)$ & .14 & 23.4 & 76.1 \\
\hline Specif. phobia & 191 & 37 & $19.4(14.0-25.7)$ & 21 & $11.0(6.9-16.3)$ & .20 & 20.7 & 85.8 \\
\hline Social phobia & 100 & 20 & $20.0(12.7-29.2)$ & 23 & $23.0(15.2-32.5)$ & .82 & 9.3 & 75.2 \\
\hline Obsessions & 31 & 10 & $32.3(16.7-51.4)$ & 7 & $22.6(9.6-41.1)$ & .66 & 47.1 & 80.0 \\
\hline Compulsions & 47 & 9 & $19.1(9.1-33.3)$ & 3 & $6.4(1.3-17.5)$ & .20 & 33.3 & 90.2 \\
\hline PTSD & 41 & 10 & $24.4(12.4-40.3)$ & 4 & $9.8(2.7-23.1)$ & .22 & 28.6 & 85.3 \\
\hline Enuresis & 89 & 11 & $12.4(6.3-21.0)$ & 12 & $13.5(7.2-22.4)$ & 1 & 26.1 & 89.0 \\
\hline
\end{tabular}

Note: ${ }^{1}$ Number of cases with symptoms combining information from parents and children. ${ }^{2}$ McNemar chi square. Bonferroni-Finner corrected $p$.

the adolescents $(95 \% \quad C I: 61.3-74.9)$ noted distress $(p=.002)$. Combining information from parent and children, $66.9 \%$ of the children $(95 \% \quad C I: 57.7$ - 75.3$)$ and $81.1 \%$ of the adolescents $(95 \% \quad C I: 75.2$ - 86.2) were distressed by their psychological symptoms $(p=.004)$.

With regard to individual disorders, the only significant difference that emerged was that adolescents with MDD suffered more distress than children (combined: children: $31.3 \%$, adolescents: $60.6, p<.0005$ ).

A sex by age interaction was studied for all the individual disorders. Sex and age were moderator variables only in ADHD. In adolescents with ADHD there was more distress in boys than in girls with an odds ratio $(O R)$ equal to 5.4 (95\% CI: 1.75 to $16.7, p=.003)$. In children, there was more distress in girls than in boys although the difference was not significant $(O R=1.7$, $95 \% C I$ : .64 to $6.8, p=.280$ ).

\section{Parent-child agreement in report of distress}

The structure of the diagnostic interview permits the interviewer to register the clinical significance criterion of impairment (and the new addition of distress) in the presence of symptomatology. Table 1 summarizes the percentages of distress reported separately by parents and children for the cases with symptoms. There were no differences in the frequency of distress reported by children and their parents. Distress caused by symptoms (subthreshold or with the full diagnosis) reported by parent or children was present in $76.1 \%$ of the cases (95\% CI: 71.1 to 80.6 ). Significant distress because of any symptom/disorder present in the interview was reported by $56.7 \%$ of the parents and $58.2 \%$ of the chil-
Table 2. Relationship between Distress and Impairment.

\begin{tabular}{|c|c|c|c|c|c|c|c|}
\hline \multirow[b]{2}{*}{ Diagnosis } & \multirow[b]{2}{*}{ Inf. } & \multirow{2}{*}{$\begin{array}{l}\text { Cases with } \\
\text { symptoms }\end{array}$} & \multicolumn{2}{|c|}{$\%$ of reported } & \multirow[b]{2}{*}{$p^{1,2}$} & \multicolumn{2}{|c|}{$\begin{array}{c}\text { Association } \\
\text { between distress } \\
\text { \& impairment }\end{array}$} \\
\hline & & & Distress & Impairment & & $O R^{3}$ & $p^{2}$ \\
\hline \multirow{2}{*}{ Global } & $\mathrm{C}$ & 289 & 66.1 & 77.2 & .006 & 3.1 & .001 \\
\hline & $\mathrm{P}$ & 303 & 61.7 & 85.1 & $<.001$ & 4.3 & $<.001$ \\
\hline \multirow{2}{*}{ ADHD } & $\mathrm{C}$ & & & & & & \\
\hline & $\mathrm{P}$ & 210 & 27.6 & 80.5 & $<.001$ & 6.0 & .011 \\
\hline \multirow{2}{*}{ ODD } & $\mathrm{C}$ & 104 & 35.6 & 76.9 & $<.001$ & 5.8 & .015 \\
\hline & $\mathrm{P}$ & 152 & 35.5 & 84.9 & $<.001$ & 3.2 & .074 \\
\hline \multirow{2}{*}{$\mathrm{CD}$} & $\mathrm{C}$ & 159 & 23.3 & 62.3 & $<.001$ & 9.9 & .001 \\
\hline & $\mathrm{P}$ & 133 & 16.3 & 66.7 & $<.001$ & 3.2 & .096 \\
\hline \multirow{2}{*}{ Alcohol } & $\mathrm{C}$ & 28 & 17.9 & 35.7 & .223 & 10.4 & .093 \\
\hline & $\mathrm{P}$ & 5 & 0.0 & 80.0 & - & - & - \\
\hline \multirow{2}{*}{ Marijuana } & $\mathrm{C}$ & 37 & 10.8 & 40.5 & .013 & 6.7 & .188 \\
\hline & $\mathrm{P}$ & 10 & 30.0 & 70.0 & .263 & - & - \\
\hline \multirow{2}{*}{ Other drugs } & $\mathrm{C}$ & 8 & 50.0 & 75.0 & .596 & - & - \\
\hline & $\mathrm{P}$ & 1 & - & - & - & - & - \\
\hline \multirow{2}{*}{ MDD } & $\mathrm{C}$ & 164 & 50.0 & 47.6 & .717 & 4.2 & .001 \\
\hline & $\mathrm{P}$ & 139 & 48.9 & 61.9 & .003 & 19.5 & $<.001$ \\
\hline \multirow{2}{*}{ Manic Episode } & $\mathrm{C}$ & 14 & 21.4 & 28.6 & 1.0 & 8.6 & .237 \\
\hline & $\mathrm{P}$ & 5 & 20.0 & 40.0 & 1.0 & - & - \\
\hline \multirow{2}{*}{ Dysthymia } & $\mathrm{C}$ & 32 & 56.3 & 68.8 & .501 & 2.4 & .325 \\
\hline & $\mathrm{P}$ & 36 & 50.0 & 80.6 & .008 & 9.1 & .079 \\
\hline \multirow{2}{*}{ SAD } & $\mathrm{C}$ & 76 & 30.3 & 21.1 & .231 & 11.4 & .001 \\
\hline & $\mathrm{P}$ & 55 & 23.6 & 32.7 & .848 & 33.7 & .007 \\
\hline \multirow{2}{*}{ GAD } & $\mathrm{C}$ & 123 & 39.8 & 30.1 & .178 & 3.1 & .015 \\
\hline & $\mathrm{P}$ & 84 & 33.3 & 40.5 & .460 & 3.4 & .023 \\
\hline \multirow{2}{*}{ Specific Phobia } & $\mathrm{C}$ & 145 & 25.5 & 15.9 & .045 & 8.6 & $<.001$ \\
\hline & $\mathrm{P}$ & 108 & 19.4 & 25.9 & .342 & 7.6 & $<.001$ \\
\hline \multirow{2}{*}{ Social phobia } & $\mathrm{C}$ & 62 & 32.3 & 33.9 & 1.0 & 1.4 & .597 \\
\hline & $\mathrm{P}$ & 52 & 44.2 & 46.2 & 1.0 & 6.2 & .012 \\
\hline \multirow{2}{*}{ Obsessions } & $\mathrm{C}$ & 22 & 45.5 & 13.6 & .092 & 4.3 & .327 \\
\hline & $\mathrm{P}$ & 14 & 50.0 & 28.6 & .466 & 27.9 & .082 \\
\hline \multirow{2}{*}{ Compulsions } & $\mathrm{C}$ & 33 & 27.3 & 3.0 & .027 & - & - \\
\hline & $\mathrm{P}$ & 20 & 15.0 & 15.0 & 1.0 & 2.7 & .535 \\
\hline \multirow{2}{*}{ PTSD } & $\mathrm{C}$ & 23 & 43.5 & 26.1 & .318 & 48.7 & .106 \\
\hline & $\mathrm{P}$ & 24 & 16.7 & 37.5 & .263 & 8.3 & .129 \\
\hline \multirow{2}{*}{ Enuresis } & $\mathrm{C}$ & 57 & 19.3 & 14.0 & .596 & 15.1 & .015 \\
\hline & $\mathrm{P}$ & 58 & 20.7 & 25.9 & .657 & 6.5 & .016 \\
\hline
\end{tabular}

Note: Inf.: Informers: C: Children; P: Parents. ${ }^{1} \mathrm{McNemar} \chi^{2} .{ }^{2}$ Bonferroni-Finner's $p$. ${ }^{3} \mathrm{OR}$ adjusted by sex and age. 
Table 3. Relationship between Diagnosis and Distress ${ }^{1}$.

\begin{tabular}{|c|c|c|c|c|c|c|c|c|}
\hline & \multicolumn{4}{|c|}{ Children } & \multicolumn{4}{|c|}{ Parents } \\
\hline & \multicolumn{2}{|c|}{$\%$ distress $(N)$} & \multirow[b]{2}{*}{$O R^{2}$} & & \multicolumn{2}{|c|}{$\%$ distress $(N)$} & \multirow[b]{2}{*}{$O R^{2}$} & \multirow[b]{2}{*}{$p$} \\
\hline & $\begin{array}{c}\text { Diagnosis } \\
\text { present }\end{array}$ & $\begin{array}{c}\text { Diagnosis } \\
\text { absent }\end{array}$ & & $p^{3}$ & $\begin{array}{c}\text { Diagnosis } \\
\text { present }\end{array}$ & $\begin{array}{c}\text { Diagnosis } \\
\text { absent }\end{array}$ & & \\
\hline ADHD & & & & & $40.4(89)$ & $18.2(89)$ & 2.9 & .007 \\
\hline ODD & $38.0(71)$ & $30.3(33)$ & 1.8 & .285 & $40.0(110)$ & $23.8(42)$ & 2.1 & .193 \\
\hline CD & $31.0(29)$ & $21.5(130)$ & 1.7 & .306 & $23.5(17)$ & $15.1(106)$ & 1.6 & .499 \\
\hline Alcohol & $40.0(5)$ & $13.0(23)$ & 3.7 & .306 & - & - & - & $1^{4}$ \\
\hline Marihuana & $37.5(8)$ & $3.4(29)$ & 41.6 & .057 & $100(1)$ & $22.2(9)$ & - & $.337^{4}$ \\
\hline Other drugs & $100(4)$ & 0 (4) & - & $.057^{4}$ & - & - & - & \\
\hline MDD & $86.7(60)$ & $28.6(105)$ & 11.3 & $<.001$ & $83.3(54)$ & $26.4(87)$ & 12.5 & $<.001$ \\
\hline DD & $76.5(17)$ & $33.3(15)$ & 6.0 & .210 & $60.9(23)$ & $30.8(13)$ & 3.6 & .206 \\
\hline SAD & $71.4(14)$ & $21.0(62)$ & 11.6 & .012 & $56.3(16)$ & $10.3(39)$ & 32.6 & .010 \\
\hline GAD & $56.7(67)$ & $19.3(57)$ & 5.1 & .001 & $42.1(38)$ & $26.1(46)$ & 1.9 & .315 \\
\hline Specific phobia & $62.1(29)$ & $16.4(116)$ & 8.3 & $<.001$ & $24.6(57)$ & $13.5(52)$ & 1.9 & .315 \\
\hline Social phobia & $42.1(19)$ & $27.9(43)$ & 1.7 & .387 & $57.6(33)$ & $21.1(19)$ & 4.1 & .011 \\
\hline Obsessions & $70.0(10)$ & $25.0(12)$ & 6.9 & .073 & $100(3)$ & $36.4(11)$ & - & $.315^{4}$ \\
\hline Compulsions & $42.9(14)$ & $15.8(19)$ & 3.5 & .185 & $33.3(6)$ & $7.1(14)$ & 7.2 & .315 \\
\hline PTSD & $100(6)$ & $23.5(17)$ & - & $.006^{4}$ & $100(1)$ & $13.0(23)$ & - & $.315^{4}$ \\
\hline Enuresis & $26.8(41)$ & $0(16)$ & - & $.057^{4}$ & $85.6(39)$ & $10.5(19)$ & 3.5 & .315 \\
\hline
\end{tabular}

Note: ${ }^{1}$ Distress scores 3 and 4 (Fairly-a lot) were considered for the analysis. ${ }^{2} O R$ adjusted by sex and age. ${ }^{3}$ Bonferroni-Finner's $p .{ }^{4}$ Not adjusted Fisher's exact $p$.

dren $(p=.810)$. There was a tendency for children with conduct disorder, GAD and specific phobia to report more distress than their parents. However, parents were more likely to report their children were distressed as compared to self-reports of children with ODD (these comparisons were significant before Bonferroni-Finner correction). Agreement between parent and child on the presence of distress was very low; however, on the absence of distress it was higher.

\section{Relationship between distress and impairment}

Table 2 summarizes the relationship between distress and impairment for every disorder. Results show that an association exists between distress and functional impairment in that higher functional impairment was related to higher personal distress. Associations were not significant after Bonferroni-Finner correction but OR were always bigger than 1 . In general, disorders caused less personal distress than functional impairment. When the child was the informant, distress was reported more frequently than impairment in specific phobia and compulsions. Parents always identified more impairment than distress. Internalizing disorders (SAD, GAD, social phobia, PTSD) and enuresis cause similarly functional impairment or distress. Externalizing disorders always caused more impairment than distress.

\section{Association between diagnosis and distress}

When a diagnosis was present, MDD, SAD, GAD, specific phobia and PTSD were significantly associated with distress according to children's reports (marijuana and other drug dependence, obsessions, and enuresis were almost significant). Diagnoses derived from parents' information, in general, were not related to distress. The excep- tions were ADHD, MDD, SAD and social phobia; according to parents, these disorders caused significant distress in their children.

\section{Association between subthreshold disorders and distress}

In order to understand if children that did not present the complete disorder suffer distress by the symptomatology, this group was compared with children with the full diagnosis. Table 4 shows that, in comparison with children that met full DSM-IV criteria, subthreshold children suffered similar psychological distress in CD, DD, phobias and compulsions. In the remaining cases, full diagnosis was most associated with distress.

Table 4. Relationship between Different Categories of Symptomatology and Psychological Distress.

\begin{tabular}{lcccc}
\hline & $\begin{array}{c}\text { Symptoms } \\
\text { without im- } \\
\text { pairment - A }\end{array}$ & $\begin{array}{c}\text { \% distress (N) } \\
\text { Subthreshold } \\
\text { Diagnosis } \\
\text { present - B }\end{array}$ & $\begin{array}{c}\text { Comparison } \\
\text { Diagnosis } \\
\text { present - C }\end{array}$ & $\begin{array}{c}\text { B vs. C } \\
\text { OR }^{1}(\boldsymbol{p})\end{array}$ \\
\hline ADHD & $8.8(34)$ & $22.6(84)$ & $40.4(89)$ & $2.2(.022)$ \\
ODD & $12.5(8)$ & $20.7(29)$ & $47.1(153)$ & $3.4(.011)$ \\
CD & $6.5(62)$ & $35.8(95)$ & $40.0(45)$ & $1.2(.651)$ \\
Alcohol & $5.9(17)$ & $0(2)$ & $57.1(7)$ & - \\
Marihuana & $5.0(20)$ & $0(5)$ & $30(10)$ & - \\
MDD & $32.2(115)$ & $50.0(24)$ & $92.9(70)$ & $8.6(.001)$ \\
DD & $66.7(3)$ & $42.9(14)$ & $72.2(36)$ & $3.3(.072)$ \\
SAD & $22.2(2)$ & $0(2)$ & $62.1(29)$ & - \\
GAD & $22.2(9)$ & $23.8(42)$ & $55.2(96)$ & $3.9(.002)$ \\
Specific & $13.1(107)$ & $37.5(8)$ & $46.1(76)$ & $1.5(.608)$ \\
phobia & & & & \\
Social & $27.3(44)$ & $16.7(6)$ & $57.1(49)$ & $6.4(.104)$ \\
phobia & $33.3(3)$ & $30.0(20)$ & $75.0(8)$ & $6.7(.048)$ \\
Obsessions & $5.9(17)$ & $20.0(10)$ & $35.0(20)$ & $2.1(.407)$ \\
Compulsions & $0(6)$ & $20.0(20)$ & $88.9(9)$ & $26.9(.015)$ \\
PTSD & & & & \\
\hline
\end{tabular}

Note: ${ }^{1}$ OR adjusted by sex and age. 


\section{Association of DSM-IV symptoms with distress}

Table 5 synthesizes the relationships of individual symptoms of disorders with distress and impairment (at home, at school or with friends) adjusted by sex, age and other comorbidity (number of diagnoses present) combining information from parent and children. The symptoms of "difficulty sustaining attention", "avoids sustained mental effort" from ADHD, "loses temper", "argues", "defies", "touchy" and "angry" from ODD, and "broken into other house" from CD were significantly associated with impairment at home, school or with friends. Considering individual externalizing symptoms, only symptoms of ODD were associated with psychological distress ("deliberately annoys people" and "angry and resentful"). However, the number of conduct disorder symptoms and the number of ODD symptoms was also related to distress; that is, the risk of psychological distress is multiplied by 1.55 for every ODD symptom present, and by 1.83 (vs. 1.26 for impairment) for every CD symptom.

All the symptoms of major depression caused impairment and distress. All the symptoms of dysthymic disorder caused distress and also impairment, for three of them, ("low selfesteem", "concentration/indecisiveness", "hopelessness"). All the symptoms of GAD caused psychological disturbance and three also affected daily functioning as well. No specific separation anxiety symptom caused individual distress or impairment, but all symptoms combined (total) were related to both distress and impairment.

Association of distress and perception of problems, need for help and use of services

Questions pertaining to perception of problems, need for help and use of services were associated with any distress. The sex and age adjusted OR of perceiving need for psychological help in the presence of any distress was 2.7 (95\% CI: 1.6 - 4.4) from children's information, and $1.9(95 \%$ CI: 1.01 - 3.7) from parents' information. Significant caretakers' perceptions of the child's psychological problems were not significantly associated with psychological distress (parents: $O R=2.6 ; 95 \% C I: 0.4$ - 16.5; teachers: $O R=0.8 ; 95 \% C I: 0.4$ - 1.3). The presence of distress did not cause more mental health outpatient services use $(O R=1.5 ; 95 \% \quad C I: 0.2-15.2)$ nor more psychological treatments in the last year $(O R=2.4 ; 95 \% C I: 0.9-6.2)$.

\section{Discussion}

A substantial number of children attending consultation (76\%) suffer distress caused by internalizing and externalizing psychological symptoms. Psychological distress is more likely to affect girls and adolescents, is usually related to a diagnosis derived from children rather than parents, is significantly
Table $5^{1}$. Association of individual symptoms with psychological distress and impairment.

\begin{tabular}{|c|c|c|c|c|}
\hline \multirow[b]{2}{*}{ Parent-child combined reports } & \multicolumn{2}{|c|}{ Distress } & \multicolumn{2}{|c|}{ Any Impairment } \\
\hline & $O R^{2}$ & $p^{3}$ & $O R^{2}$ & $p^{3}$ \\
\hline \multicolumn{5}{|l|}{ Attention deficit-hyperactivity disorder } \\
\hline 1b. Difficulty sustaining attention & & & 2.95 & .018 \\
\hline 1f. Avoids sustained mental effort & & & 2.74 & .027 \\
\hline Number of ADHD symptoms & & & 1.11 & .003 \\
\hline \multicolumn{5}{|l|}{ Oppositional Defiant Disorder } \\
\hline A1. Loses temper & & & 4.84 & .012 \\
\hline A2. Argues with adults & 2.79 & $>.05$ & 4.52 & .008 \\
\hline A3. Often defies & & & 3.26 & .012 \\
\hline A4. Deliberately annoys people & 2.48 & .032 & 2.23 & $>.05$ \\
\hline A6. Touchy & 1.97 & $>.05$ & 3.37 & .012 \\
\hline A7. Angry and resentful & 2.49 & .032 & 2.98 & .013 \\
\hline Number of ODD symptoms & 1.55 & $<.001$ & 2.07 & $<.001$ \\
\hline \multicolumn{5}{|l|}{ Conduct Disorder } \\
\hline A10. Broken into other's house & & & 3.15 & .004 \\
\hline A11. Often lies & & & 2.47 & .051 \\
\hline Number of CD symptoms & 1.83 & $<.001$ & 1.26 & .012 \\
\hline \multicolumn{5}{|l|}{ Major depression } \\
\hline A1. Depressed mood & 10.83 & $<.001$ & 8.07 & $<.001$ \\
\hline A2. Diminished interest or pleasure & 6.26 & $<.001$ & 3.28 & $<.001$ \\
\hline A3. Weight loss or gain & 5.10 & $<.001$ & 3.40 & $<.001$ \\
\hline A4. Insomnia /hypersomnia & 5.19 & $<.001$ & 3.71 & $<.001$ \\
\hline A5. Psychomotor agitation/retardation & 3.25 & $<.001$ & 1.81 & .044 \\
\hline A6. Fatigue & 7.74 & $<.001$ & 6.59 & $<.001$ \\
\hline A7. Wortlessness/guilt & 3.86 & $<.001$ & 6.51 & $<.001$ \\
\hline A8. Difficulty for con & 6.11 & $<.001$ & 3.98 & $<.001$ \\
\hline Number of MDD symptoms & 1.82 & $<.001$ & 1.63 & $<.001$ \\
\hline \multicolumn{5}{|l|}{ Dysthymic disorder } \\
\hline B1. Poor appetite or overeating & 4.61 & .025 & & \\
\hline B2. Insomnio/hypersomnia & 5.85 & .015 & & \\
\hline B3. Low energy/Fatigue & 3.18 & .038 & & \\
\hline B4. Low self-esteem & 4.58 & .015 & 8.35 & .010 \\
\hline B5. Poor concentration/indecisiveness & 5.19 & .015 & 5.52 & .020 \\
\hline B6. Hopelessness & 6.60 & .006 & 5.65 & .017 \\
\hline Number of DD symptoms & 2.32 & $<.001$ & 2.08 & .001 \\
\hline \multicolumn{5}{|l|}{ Separation Anxiety Disorder } \\
\hline Number of SAD symptoms & 1.37 & 028 & 1.54 & .004 \\
\hline \multicolumn{5}{|l|}{ Generalized Anxiety Disorder } \\
\hline B. Difficulty to control de worry & 4.39 & .003 & 2.82 & .021 \\
\hline C2. Easily fatigued & 1.99 & .045 & 2.53 & .021 \\
\hline C3. Difficulty concentrating & 2.58 & .040 & & \\
\hline C4. Irritability & 3.07 & .003 & 3.07 & .007 \\
\hline C5. Muscle tension & 2.43 & .017 & & \\
\hline C6. Sleep disturbance & 4.07 & .003 & & \\
\hline Number of GAD symptoms & 1.41 & .001 & 1.36 & .002 \\
\hline
\end{tabular}

associated with subthreshold conditions, and is a marker of perception of need of psychological help. Individual symptoms of depression, dysthymia, generalized anxiety disorder and oppositional defiant disorder were most associated with psychological distress. The agreement between the information given by children and their parents on the presence of psychological distress was low.

As expected, internalizing disorders (MDD, obsession, GAD, DD, panic disorder, PTSD, SAD) are most likely to be associated with subjective distress. Phares and Compas (1990) 
also found that adolescents were significantly more distressed by internalizing behaviors as opposed to externalizing behaviors. However, though it is thought that internalizing disorders must be associated with psychological distress, not all cases with these disorders report distress. Dubow et al. (1990), in junior and high school, found that only half of the adolescents who experienced problems were troubled by them. Similarly, in the Beals et al. (2004) study with adults, even a lower proportion (less than half) of the subjects reported being upset by their full internalizing DSM-IV diagnosis. Still, Phares and Danforth (1994) reported that clinical adolescents were the least motivated to change their behavior compared to parents and teachers, but that they were significantly more likely to alter internalizing rather than externalizing problems. These data highlight the importance of assessing distress since it can be a marker of motivation to change.

Individual internalizing symptoms were more associated with distress than individual externalizing symptoms. The association of individual ODD symptoms with distress was remarkable, meaning that ODD symptoms are also very painful. Although the ODD diagnosis was not related to psychological distress, specific individual symptoms and the number of symptoms were associated with distress. In other words, ODD as a clinical syndrome impairs daily functioning, but the presence of some individual symptoms or the aggregation of some of them also causes psychological pain. Individual symptoms comprising the other externalizing disorders, ADHD and CD, did not cause psychological pain. All the symptoms of depressive disorders were associated with significant psychological distress. Individual symptoms of major depression were as impairing as they were distressing. The case of anxiety disorders is more variable and not all the symptoms caused distress as might be expected. Though only GAD individual symptoms were related to psychological distress (and none of the SAD), the total number of symptoms of these disorders was associated with distress (and also impairment). Bird et al. (2000) pointed out in a study comparing specific vs. global measures of impairment that impairment was a global concept and that it was very "difficult for respondents to parcel out impairment among particular symptoms or diagnostic entities" (p.1187). Something similar may be occurring when assessing distress in separation anxiety; it is not individual symptoms that are painful for the child but their additive and global effect. Furthermore, it is important to keep in mind that many families with children who suffer from separation anxiety are overprotective and have simply adapted to the disorder, reducing awareness of the problem in terms of individual symptoms and their consequences.

Considering all the symptoms together, girls self-report significantly more distress than boys. Parents also reported that girls were more distressed than boys, but in this case differences did not reach significance $(\mathrm{p}=.055)$. Girls specifically report more distress caused by MDD symptoms and by
PTSD. Salokangas, Vaahtera, Pacriev, Sohlman, and Lehtinen (2002) have reported that with adults, sadness is not only more common in women than in men among the general population, but also that women are able to identify it more accurately because of their socialization experiences. It may be that this is also the case with emotional distress in that girls are better able to identify the feeling compared to boys and, hence, report it more frequently. In community studies using questionnaires, gender differences in distress are less consistent. While Dubow et al. (1990) noted that females' experiences more distress, Phares and Compas (1990) did not find any difference. The importance of considering gender differences in the expression of psychopathology in nosological systems has been remarked by Hudziak, Achenbach, Althoff, and Pine (2007). Because of the sex differences found in our study, all analyses were controlled by this variable. Still, future research should investigate why girls -who suffer more psychological distress than boysare brought less frequently than boys for consultation (Alegría, Canino, Ramírez, Chavez, \& Rusch, 2004; Burns et al., 1995).

As children get older, psychological symptoms are more distressful. Studies about impairment have previously reported that psychological disorders are more severe in adolescents than in children (Ezpeleta, Granero, de la Osa, \& Guillamon, 2000). Furthermore, it seems from our results that adolescents suffer from more severe disorders that cause them more discomfort relative to children, or else they are better able to identify this feeling.

These results on parents and children underscore the importance of obtaining children's information about their symptomatology and how they experience it. Lack of agreement between parent and children relating to impairment has been recently documented by Wille, Bettge, Wittchen, RavensSieberer, and Study (2008), but agreement between parent and children relating to distress of the child has not been previously reported. Parents and children do not agree on the presence of distress in their reports; children tended to report a higher frequency of distress by internalizing symptoms than their parents and they report more distress than impairment caused by symptoms whereas parents always identify more impairment than distress. Along those same lines, diagnoses derived from children's information were associated with distress, whereas rarely were diagnoses from parents' reports associated significantly with distress. These data suggest the importance of considering the best informants for these symptoms given that children are more likely than parents to recognize distress and thus their information is critical for an accurate diagnostic picture. Further, it seems that the experience of distress is an important variable with regard to recognizing the need for mental health help. When distress was present, the probability that both parent and children perceived they needed help was significantly increased in comparison to the absence of distress. As mentioned earlier, motivation to attend consultation is a key variable for the successful outcome of treatment. 
Results showed a linear tendency with psychological distress in that the frequency of distress was greater in the groups with the full diagnosis (data not shown). The frequency of distress in children with subthreshold DD, phobias and compulsions was similar to those with the full diagnosis, suggesting that personal suffering in these subthreshold conditions should be treated. This is especially relevant when considering the finding that distress is related to perceived need of psychological help. Angold et al. (1999) had reported that impaired cases without diagnosis should be considered as cases with psychiatric disorders and hence, they should receive the appropriate treatment. Our data indicate that these conditions are associated not only with difficulties in functioning, but also with significant psychological pain.

Both measures of "clinical significance" -functional impairment and psychological distress- are significantly related such that those disorders that cause most functional impairment at home, at school or with friends also cause high internal disturbance. With regard to frequency of occurrence, functional impairment is more emphasized and reported than distress in many of the disorders, perhaps because functional impairment is more observable than subjective psychological distress. Children recognize significantly more impairment than distress in ODD, CD and marijuana abuse, and more psychological distress than impairment in specific phobia and compulsions. As expected by the nature of the information registered, parents always attributed significantly more impairment than distress. These results could be useful for refining the clinical significance criterion developmentally according to the informant.

\section{Clinical implications}

Information about how children and their parents recognize and report painful psychological symptoms in children is relevant to better understanding how disorders manifest and for establishing who the best informant is and who must be treated. It also has implications for the definition of the disorders, at least as they are conceived currently in DSM. Additionally, the assessment of distress can help clinicians better understand the cases and to identify subsyndromal cases in need of treatment. Given the internalized nature of psychological distress, we have seen that children are the best reporters of this feeling. Psychological distress is expected in internalizing disorders but we found that externalizing symptoms/disorders also cause psychological disturbance in children, although to a lesser degree. Further studies should determine if most distressed cases have different treatment outcomes. Our results can also aid in resolving the ambivalence in the application of the clinical significance criterion and be of help in determining if disability (distress and/or impairment) and diagnosis must go together or not.

Meanwhile, for the aforementioned reasons and because psychological distress is an important indicator of suffering and a good predictor of perception of need for psychological help, we recommend it be screened through a diagnostic psychological assessment and to include questions about distress in structured diagnostic interviews.

\section{Limitations}

Although the large sample size of this study, the low prevalences for symptoms of some disorders may have decreased statistical power. In addition, cases included pertain to a clinical sample attending consultation and it has been shown that cases who ask for psychological help do not represent the population of cases with the disorder.

\section{References}

Alegría, M., Canino, G., Ramírez, R., Chavez, L., \& Rusch, D. (2004). Understanding caregivers' help-seeking for Latino children's mental health care use. Medical Care, 42, 447-455.

American Psychiatric Association. (1994). DSM-IV Diagnostic and statistical manual of mental disorders (4th ed.). Washington, DC: Author.

Angold, A., Costello, E. J., Farmer, E., Burns, B. J., \& Erkanli, A. (1999). Impaired but undiagnosed. Journal of the American Academy of Child and Adolescent Psychiatry, 38, 129-137.

Antony, M. M., Moras, K., Meadow, E. A., Di Nardo, P. A., Utech, J. E., \& Barlow, D. H. (1994). The diagnostic significance of functional impairment and subjective distress criterion: An ilustration with the DSM-III-R anxiety disorders. Journal of Psychopathology and Behavioral Assessment, 16, 253-263.

Beals, J., Novins, D. K., Spicer, P., Orton, H. D., Mitchell, C. M., Barón, A. E., et al. (2004). Challenges in operationalizing the DSM-IV clinical significance criterion. Archives of General Psychiatry, 61, 1197-1207.

Beutler, L. E., Malik, M., Talebi, H., Fleming, J., \& Moleiro, C. (2004). Use of psychological tests/instruments for treatment planning. In M. E. Maruish (Ed.), The use of psychological testing for treatment planning and outcomes assessment (Vol. 1, pp. 111-145). Mahwah, NJ: Lawrence Earlbaum.

Bird, H., Davies, M., Fisher, P., Narrow, W., Jensen, P., Hoven, C., et al. (2000). How specific is specific impairment? Journal of the American Academy of Child and Adolescent Psychiatry, 39, 1182-1189.

Burns, B. J., Costello, A. J., Angold, A., Tweed, D. L., Stangl, D., Farmer, E., et al. (1995). Children's mental health service use across service sectors. Health Affairs, 14, 147-159.

Drabick, D. A. G. (2009). Paradigm shift toward a mixed categorical-dimensional classification system? Clinical Psychology-Science and Practice, 16, 41-49

Dubow, E. F., Lovko, K. R., \& Kausch, D. F. (1990). Demo- 
graphic differences in adolescents' health concerns and perceptions of helping agents. Journal of Clinical Child Psychology, 19, 44-54.

Ezpeleta, L., de la Osa, N., Júdez, J., Doménech, J. M., Navarro, J. B., \& Losilla, J. M. (1997). Diagnostic agreement between clinician and the Diagnostic Interview for Children and Adolescents - DICA-R in a Spanish outpatient sample. Journal of Child Psychology and Psychiatry, 38, 431-440.

Ezpeleta, L., Granero, R., de la Osa, N., \& Guillamon, N. (2000). Predictors of functional impairment in children and adolescents. Journal of Child Psychology and Psychiatry, 41, 793-801.

Finner, H. (1993). On A Monotonicity Problem in Step-Down Multiple Test Procedures. Journal of the American Statistical Association, 88, 920-923.

Goodman, R., Ford, T., Richards, H., Gatward, R., \& Meltzer, H. (2000). The Development and Well-Being Assessment: Description and initial validation of an integrated assessment of child and adolescent psychopathology. Journal of Child Psychology and Psychiatry, 41, 645-655.

Hollingshead, A. B. (1975). Four factor index of social status. New Haven, CT: Unpublished manuscript, Yale University, Department of Sociology.

Hudziak, J. J., Achenbach, T. M., Althoff, R. R., \& Pine, D. S. (2007). A dimensional approach to developmental psychopathology. International Journal of Methods in Psychiatric Research, 16, S16-S23.

Kaufman, J., Birmaher, B., Brent, D. A., Rao, U., Flynn, C., Moreci, P., et al. (1997). Schedule for Affective Disorders and Schizophrenia for School-Age Children-Present and Lifetime Version (K-SADS-PL): initial reliability and validity data. Journal of the American Academy of Child \& Adolescent Psychiatry, 36, 980-988.

Lehman, A. F., Alexopoulos, G., Goldman, H., Jeste, D., \& Ustun, B. (2002). Mental disorder and disability. In D. J. Kupfer, M. B. First \& D. A. Regier (Eds.), A Research Agenda for DSM-V (pp. 201-218). Washington, DC: American Psychiatric Press.

Lewinsohn, P. M., Solomon, A., Seeley, J. R., \& Zeiss, A. (2000). Clinical implications of 'subthreshold' depressive symptoms. Journal of Abnormal Psychology, 109, 345-351.

Maser, J. D., Norman, S. B., Zisook, S., Everall, I. P., Stein, M. B., Schettler, P. J., et al. (2009). Psychiatric nosology is ready for a paradigm shift in DSM-V. Clinical Psychology: Science and Practice, 16, 24-40.

Panichelli-Mindel, S. M., Flannery-Schroeder, E., Kendall, P.
C., \& Angelosante, A. G. (2005). Disclosure of distress among anxiety-disordered youth: Differences in treatment outcome. Journal of Anxiety Disorders, 19, 403-422.

Phares, V., \& Compas, B. E. (1990). Adolescents' subjective distress over their emotional/behavioral problems. Journal of Consulting and Clinical Psychology, 58, 596-603.

Phares, V., \& Danforth, J. S. (1994). Adolescents', parents', and teachers' distress over adolescents' behavior. Journal of Abnormal Child Psychology, 22, 721-732.

Pincus, H. A., Davis, W. W., \& McQueen, L. E. (1999). 'Subthreshold' mental disorders: A review and synthesis of studies on minor depression and other 'brand names'. British Journal of Psychiatry, 174, 288-296.

Reich, W. (2000). Diagnostic Interview for Children and Adolescents (DICA). Journal of the American Academy of Child and Adolescent Psychiatry, 39, 59-66.

Salokangas, R. K. R., Vaahtera, K., Pacriev, S., Sohlman, B., \& Lehtinen, V. (2002). Gender differences in depressive symptoms. An artefact caused by measurement instruments? Journal of Affective Disorders, 68, 215-220.

Silverman, W. K., Albano, A. M., \& Barlow, D. H. (1994). Anxiety Disorders Interview Schedule for DSM-IV: Child and Parent Versions. SUNY Albany: Graywind Publications Inc.

Spitzer, R. L., \& Wakefield, J. (1999). DSM-IV diagnostic criterion for clinical significance: Does it help solve the false positive problems? American Journal of Psychiatry, 156, 1856-1864.

Todd, R. D., Joyner, C. A., Heath, A. C., Neuman, R. J., \& Reich, W. (2003). Reliability and stability of a semistructured DSM-IV interview designed for family studies. Journal of the American Academy of Child and Adolescent Psychiatry, 42, 1460-1468.

Üstun, B., \& Chatterji, S. (1997). Editorial: Measuring functioning and disability-a commen framework. International Journal of Methods in Psychiatric Research, 7, 79-83.

Wille, N., Bettge, S., Wittchen, H. U., Ravens-Sieberer, U., \& Study, G. B. (2008). How impaired are children and adolescents by mental health problems? Results of the BELLA study. European Child \& Adolescent Psychiatry 17, 42-51.

Fecha de recepción: 10 de abril de 2009 Fecha de aceptación: 22 de abril de 2009 